\title{
A REABILITAÇĀO DO SENSÍVEL EM MERLEAU-PONTY TENDO COMO PANO DE FUNDO A FILOSOFIA DE KANT
}

Urbano Mestre Sidoncha

Universidade da Beira Interior

Nous voyens les choses mêmes, le monde est cela que nos voyons.'

Maurice Merleau-Ponty

\section{Crítica pontiana à tradição da desfiguração do sensível}

"Reabilitar" inscreve no seu campo semântico, absolutamente simétrico e exaurido de qualquer mescla de ambiguidade, a necessidade de uma ilibação e a ideia conexa de uma regeneração. Tais noções emergem aqui como a expressão liminar e a categórica explicitação do seu teor de sentido. Mas uma tal enunciação, que aqui se apresenta ainda na sua expressão mais balbuciante, permite ilustrar já aquela que é uma das decisões teóricas de fundo de maior monta na filosofia de Merleau-Ponty, e que versa, precisamente, sobre a inevitabilidade desse projecto de revalorização do sensível. Num tal enquadramento teórico que assim se desvela, a tarefa primeira será não tanto a de interrogar o sentido dessa anunciada reabilitação, mas a de questionar a montante, numa primeira mas decisiva exigência de radicalidade - ao melhor estilo pontiano - a razão que torna necessária, e portanto, que legitima, a necessidade mesma dessa regeneração. Indaguemos, pois, sem mais delongas, de que imputações deve o sensível ser ilibado, e o que justifica derradeiramente esse aludido esforço de reabilitação. Na verdade, esta exigência, que é uma exigência de primeira hora na filosofia do nosso autor, para sempre permanecerá na sombra se não forem evidenciadas, nos seus contornos mais incisivos, as razões que, desde

1 Merleau-Ponty, M., Le Visible et l'Invisible. Paris: Gallimard, 1964, p. 17.

Phainomenon, n. ${ }^{\circ}$ 18-19, Lishoa, pp. 141-156.

DOI: 10.2478 /phainomenon-2009-0008

(C) 2009 Sidoncha. This is an open access article licensed under the Creative Commons Attribution-

NonCommercial-NoDerivs License (http://creativecommons.org/licenses/by-nc-nd/3.0/). 
logo, concorrem para a depreciação e desfiguração do sensível e, acto contínuo, aquelas que convergem para legitimar, agora a jusante, essa exigência mesma de regeneração. Veremos, se formos bem sucedidos, que é sobre esta questão mais primitiva que deverá recair a responsabilidade de elucidar os passos subsequentes da filosofia de Merleau-Ponty.

Fica entretanto evidente, pese embora a aparência imediata de contradição, que todo o empreendimento da filosofia pontiana deve a sua coerência e unidade internas à possibilidade de a compartimentar em dois momentos -autónomos mas perfeitamente solidários- que se revelarão fundamentais. O primeiro é, indiscutivelmente, um momento de crítica e de desconstrução que é dirigido a uma longa tradição de efectiva e sistemática desvalorização do sensível; um segundo, erigido sobre os escombros do primeiro, é aquele que instituirá, sobre um sensível entretanto isentado das antigas acusações, um projecto inteiramente novo e radical.

Não se pense, porém, que esta é mais uma daquelas duplicações ou cisões que Ponty verbera. Dir-se-á, metaforicamente, que esta profusão tem aqui o efeito de um diagnóstico, e não o da maleita a diagnosticar. Com efeito, se o esforço para pensar o projecto de Ponty a partir de dois momentos não é ora a expressão de uma nova e inaceitável "perturbação da visão", tal sucede não apenas porque esses momentos derradeiramente se revertem num elemento comum, mas fundamentalmente porque, do ponto de vista estritamente hermenêutico, entendemos que não haverá lugar à vaticinada reabilitação do sensível se ele não for expurgado dos antigos defeitos.

Detenhamo-nos, pois, nesta tarefa que é primeira na ordem genética das razões. Seria todavia injusto que estas considerações preliminares lançassem a suspeita de que toda a tradição filosófica, no seu conjunto, se deixa caracterizar pela metódica, efectiva e sempre reiterada desvalorização do sensível. Essa leitura não resiste evidentemente a um olhar mais circunspecto, e é infirmada no momento mesmo em que se determina, como fio condutor de uma certa forma de fazer filosofia, a ideia de revalorização do sensível. Tal não pode deixar de significar, para lá da tese axiomática que atesta um por fazer, que algo já foi efectivamente feito no sentido de colocar, sobre novas e melhores bases, a condição do sensível. Donde, quem intentar, a partir de Ponty, nivelar a tradição filosófica ocidental como era da depreciação do sensível, verá a sua pretensão consecutivamente infirmada pelos factos. Além disso, não interessa certamente a Ponty - mais solícito em embrenhar a crítica numa capa de anonimato (e permitam-me prolongar a metáfora judicial mais um pouco) identificar os culpados pela condição secundária ou subordinada do sensível. O que o motiva é certamente encontrar, no quadro dessa crítica, que é sempre a expressão de um esforço de apropriação e acolhimento da tradição, novas direcções e novos estímulos a imprimir à sua própria perspectiva filosófica. Tal significa, pois, que uma filosofia que viva de dualismos e da instituição de hierarquias sobrepairantes pode, se for convenientemente acolhida e trabalhada, ser o pretexto 
para uma orientação nova e radical, que veja justamente na supressão de tais hierarquias a sua decisão mais consequente, do ponto de vista das suas implicações futuras. O diagnóstico de uma filosofia desenraizada, bem vistas as coisas, mais não é do que o pretexto para exigir maior verticalidade e maior radicalidade; a identificação de um quadro de excessiva valorização do mental é, no fim de contas, o estímulo fundamental para a subtracção de hierarquias e para a recondução desse plano à sua vida sensível; a denúncia da excessiva autonomia do plano eidético é a indispensável condição para a fenomenalização das essências. Esse é, pois, o sentido da crítica que, em Ponty, transversalmente percorre a tradição filosófica ocidental. Tal significa, no limite, que esse primeiro momento deverá ser visto sempre como uma espécie de propedêutica, e nunca como uma crítica deslocada ou desenraizada.

\section{A apologia kantiana do sensível}

Entretanto, para um leitor ainda pouco familiarizado com os textos do fenomenólogo francês, há uma perplexidade inicial que é difícil vencer, e que se prende precisamente com esta exigência matricial de reabilitação da condição do sensível. Esta exigência, vimo-lo, é legítima, porque na sua base está uma tradição de contínua e sistemática depreciação do sensível. A perplexidade reside bem aí. Dos muitos autores que anonimamente se filiam no campo dessa aviltante tradição de sistemática depreciação do sensível, alguns haverá que dificilmente poderão, de jure, ser objecto da contundente crítica de Ponty. Kant é, claramente, um dos autores que no contexto da modernidade parece subtrair-se a essa crítica. Não cabe, no curto espaço deste trabalho, nem esse é disso que cuidamos aqui, averiguar meticulosamente a filosofia de Kant para aí coligir os pretensos indícios de um pensamento sensível. Trata-se, porém, de um autor decisivo quando se trata de determinar se há, ou não, na tradição abertamente criticada por Ponty, espaço para a valorização do sensível. Esta preferência por Kant (que é nossa, e que não poderá ser assacada ao autor) explica-se por razões diversas, que não poderíamos sumariar aqui de forma cabal. Detenhamo-nos apenas em duas: a primeira, estribada no próprio entendimento pontiano da natureza da filosofia, (tal como foi expendido no trabalho intitulado Signes), é aquela que sobrevém na consideração segundo a qual quando se elege uma perspectiva concreta, de certa forma é toda a filosofia que se oferece à contemplação teórica; uma segunda, mais substancial, e que retira à preferência por Kant qualquer sombra de arbitrariedade, reside na compreensão do notável esforço preconizado pelo autor para reabilitar a condição do sensível. Tal não significa, porém, como bem notou Leonel Ribeiro dos Santos num trabalho intitulado "A Razão Sensível - Reflexão acerca do estatuto da sensibilidade no pensamento kantiano", que Kant seja um sensualista, ou qué esse ensejo de valorização traduza um desígnio de primeira hora da sua filo- 
sofia. Significa apenas que há aí, de facto, uma valorização do sensível que não se queda no plano do simplesmente aparente, e que, nesse sentido, deve ser levado em devida conta. Com efeito, Kant engendra uma doutrina da sensibilidade inteiramente nova e original, apostada em privilegiar não apenas o seu carácter negativo, mas - e aí reside precisamente o seu aspecto inovador - valorizando, de forma inteiramente consequente, a sua função como fonte irredutível do conhecimento humano. Nesta fase, a tese da idealidade do espaço e do tempo como condição dos fenómenos está definitivamente adquirida, e, através dela, será possível ilibar a sensibilidade de algumas das antigas imputações, como por exemplo a que determina que se trataria de uma faculdade meramente passiva, logo, de representações confusas e obscuras, logo ainda, uma faculdade cognoscitiva inferior. Afectada a nossa capacidade de representação, que, em Kant, é a categórica definição de sensibilidade, o que se prọduz é ainda a expressão de uma sucessão de representações sem unidade. Mas longe de ser apenas a expressão de uma pura diversidade que não se deixa reconduzir a qualquer forma de ligação, a função da sensibilidade deixa agora de poder ser tomada como simples afecção ou receptividade, se por ela pretendermos significar uma função meramente passiva. Isto não significa, evidentemente, que a nossa capacidade representativa esteja desobrigada de invocar uma coisa que a possa afectar, mas significa tão-somente que o fenómeno sensível, apesar de se deixar definir ainda como objecto indeterminado de uma intuição empírica, não é mais a expressão liminar de representações confusas e caóticas. Não que a função da sensibilidade, em Kant, tenha sido ampliada ao ponto em que se torna possível reivindicar competências novas: o autor dirá uma e outra vez que a sensibilidade não pensa e nada pode pensar, e que a sua irredutível função é intuir. Mas é a compreensão mesma dessa irrevogável função que a Crítica lhe imputa como sua que ora parece ter sido substancialmente alargada, de novo não ao ponto em que a função sintética do entendimento seria derradeiramente prescindível, mas como aquilo que a erige a momento incontornável do conhecimento objectivo. Essa função, na assunção plena do seu significado, não diz, pois, mera receptividade ou passividade, mas sugere por contra, e pese embora o seu carácter aparentemente paradoxal e ambíguo, "espontaneidade", ou antes (para não corrermos o risco de sermos mal interpretados) um certo tipo de espontaneidade, de tal forma que o fenómeno sensível, mais do que a expressão de um caos intuitivo, é agora liminarmente tomado como tradução fidedigna de uma tal actividade. Neste novo enquadramento que assim se perfila, quem pretenda ver na filosofia teórica de Kant - e há uma longa tradição de comentário que aí firmará seus créditos - uma simples subordinação do sensível ao inteligível, da sensibilidade ao entendimento ou, numa palavra, da afecção à função, verá consecutivamente gorado o seu intento. É bem verdade que é o próprio Kant quem sistemática e cuidadosamente reiterou a importância da distinção - expressa vigorosamente já em 1770, então com a intenção declarada de evitar todo o tipo de circulação entre os conceitos relativos ao mundo sensível e juízos 
relativos aos inteligíveis - dizia, a importância da distinção entre as representações da sensibilidade e do entendimento, entre o estético e o lógico. Todavia, essa é uma distinção que não nos permite instituir um qualquer tipo de hierarquia que promova o enobrecimento do segundo em detrimento ou em prejuízo do primeiro. Para um entendimento como o nosso, que não é intuitivo, o mesmo é dizer, originariamente criador do seu objecto, mas meramente discursivo, a sensibilidade ocupa indiscutivelmente um lugar cimeiro, que não se deixa compaginar com pretensas hierarquias. Diz Kant na Crítica da Razão Pura:

nenhuma destas qualidades [afecção e função] tem primazia sobre a outra. Sem a sensibilidade, nenhum objecto nos seria dado; sem o entendimento, nenhum seria pensado. Pensamentos sem conteúdo são vazios; intuições sem conceitos são cegas. ${ }^{2}$

Ora, uma tal decisão não pode ser interpretada senão como um momento de notável e efectiva reabilitação da condição da sensibilidade, contra a compreensão ainda depreciativa, diríamos negativa que, grosso modo, caracteriza a escola leibniziano-wollfiana. Insiste Kant:

a filosofia de Leibniz e de Wolff indicou uma perspectiva totalmente errada a todas as investigações acerca da natureza e origem dos nossos conhecimentos, considerando apenas puramente lógica a distinção entre o sensível e o intelectual, porquanto essa diferença é, manifestamente, transcendental e não se refere tão-só à sua forma clara ou obscura, mas à origem e conteúdo desses conhecimentos. ${ }^{3}$

Noutro e decisivo passo, o juízo negativo de Kant em relação a uma tal escola apresenta-se na sua expressão mais peremptória:

a teoria segundo a qual toda a nossa sensibilidade seria apenas a confusa representação das coisas [...] representa um falseamento dos conceitos de sensibilidade e de fenómeno, pelo que é vã e inútil. A diferença entre uma representação clara e uma representação obscura é apenas lógica e não se refere ao conteúdo. ${ }^{4}$

Longe, pois, de podermos apoucar a sensibilidade, relegando-a à vexatória condição de faculdade inferior, o intento kantiano traduz-se, desta feita, como bem sublinhou Leonel Ribeiro dos Santos no trabalho referido supra, na declaração formal da condição sensível do pensamento humano, desde logo, na sua afirmação no domínio cognoscitivo como condição absolutamente irrevogável do conhecimento objectivo.

Há, todavia, outros passos na filosofia kantiana que reforçam o esforço expendido a montante para uma efectiva revalorização do sensível. No último

${ }^{2}$ Kant, Immanuel, Kritik der reinen Vernunft: Crítica da Razão Pura, trad. de Alexandre Fradique Morujão, Lisboa: Fundação Calouste Gulbenkian, 1994 (3. ' edição), p. 89.

${ }^{3}$ Ibid., p. 80

${ }^{4}$ Ibid., p. 79. 
dos textos do sistema crítico de Kant, referindo-se à sensação como determinação do sentimento de prazer ou desprazer, o autor afasta a sua compreensão de uma simples representação objectiva dos sentidos para passar agora a designar aquilo que não serve absolutamente para nenhum conhecimento. Trata-se de uma sensação subjectiva, estritamente subjectiva - que não se confunde já com uma sensação objectiva, quer dizer, como aquilo que constitui a representação de um objecto - e a que Kant chama agora sentimento. Na Crítica da Faculdade do Juízo, o autor estabelece categoricamente esta distinção entre sensação e sentimento. O texto reza assim:

Representações dadas num juízo podem ser empíricas (por conseguinte estéticas). Mas o juízo que é proferido através delas é lógico se elas são referidas ao objecto somente no Juízo. Inversamente, porém, mesmo que as representações dadas fossem racionais, mas num juízo fossem referidas meramente ao sujeito (ao seu sentimento) [nesse caso] elas são sempre estéticas. ${ }^{5}$

Resulta destas concepções um significado inteiramente novo para este esforço de reabilitação da sensibilidade. Esse é também o entendimento de Leonel Ribeiro dos Santos no texto a que já fizemos menção:

[...] só neste plano se pode verdadeiramente falar de uma emancipação da sénsibilidade e de uma autonomia do estético relativamente ao entendimento e à sua Lógica. Mas pode falar-se aqui também de uma emancipação da sensibilidade relativamente a ela própria, pois o estético do juízo de gosto não é o privado e o passivo de mera sensação de agrado, mas é um juízo - embora não lógico - [juízo sem conceito] que pretende uma certa «aprovação universal», ${ }^{6}$

mas, de novo, de uma universalidade que se representa num juízo de gosto somente como subjectiva.

Estribada nesta dupla valorização do sensível, que transversalmente percorre a filosofia de Kant, a conclusão, que é magistralmente registada por Leonel R. dos Santos, parece não poder sofrer contestação

no seu conjunto, a filosofia kantiana revelar-se-á como uma verdadeira «apologia da sensibilidade» e o filósofo crítico como o seu «advogado», que a confirma nos legítimos direitos e a defende das injustas acusações do entendimento. ${ }^{7}$

5 Imm Kant, Immanuel, Kritik derUrteilskraft: Crítica da Faculdade do Juizo, trad. de António Marques e Valério Rohden. Lisboa: Imprensa Nacional-Casa da Moeda, p. 90.

6 Santos, Leonel Ribeiro dos, "A Razão Sensível - Reflexão acerca do estatuto da sensibilidade no pensamento kantiano", in Pensar a Cultura Portuguesa-Homenagem a Francisco da Gama Caeiro. Lisboa: Edições Colibri, 1993, p. 410.

${ }^{7}$ Ibid., p. 405 


\section{As insuficiências do programa kantiano}

$\mathrm{Na}$ posse destes elementos, que evidentemente apresentamos aqui totalmente despojados de qualquer intenção de exaustividade, a pergunta impõe-se com naturalidade: se Kant é um tal advogado da sensibilidade, se há aí um esforço de sistemática e efectiva reabilitação da sua condição como estrutura do nosso Gemüt - o que a permite elevar, como se viu, a fonte irredutível do conhecimento humano -, como explicar, pois, a discordância de fundo de Ponty em relação a Kant, convertendo-o em mero membro de uma tradição de desfiguração do sensível? De uma forma mais breve, o que falta à perspectiva kantiana para que ela se volva num ensejo de autêntica reabilitação da condição da sensibilidade? A resposta de Ponty, aquela que colige as razões de fundo que o impedem de assumir, sem reservas, a "herança" do kantismo no que à sensibilidade diz respeito, deixa sintetizar-se numa única mas decisiva palavra: "radicalidade". Radicalidade representa, numa primeira mas decisiva acepção, a expressão liminar da filiação de Ponty na fenomenologia, de quem, aliás, o autor colheu inúmeros ensinamentos, e de novo num duplo registo: o crítico, o que determinou o dissídio de fundo que o apartará de algumas das linhas essenciais da fenomenologia transcendental, e o acolhimento de algumas teses que servem os propósitos adstritos a esta exigência de radicalidade.

Pensada como exigência primeira da filosofia, a radicalidade traduz um convite permanente e sempre renovado para regredir às instâncias mais "arcaicas" e mais primitivas, é, numa palavra, um recuo, mas um recuo que em nenhuma circunstância sugere ou traduz retrocesso. Por contra, tomada liminarmente como exigência primeira da demanda filosófica, um tal recuo institui-se como a condição sem a qual não é possível tocar o fundo onde tudo se apoia e onde tudo se deixa legitimar. É um fundo ainda indizível, é - para retomarmos uma expressão sempre revisitada quando se trata de qualificar este fundo pré-objectivo - um logos mudo, que é, em qualquer circunstância, um logos mais fundamental, mais antigo, que o do "pensamento objectivo" (expressão que sintetiza, em Ponty, as razões da crítica dirigida à tradição). Ora, esta exigência de radicalidade, esta busca do originário, não é um processo que possa repousar sobre um sujeito constituinte ou um sujeito absoluto, aquele que nos projecta para diante do objecto que ele próprio constitui e que, ao fazê-lo, reabilita a tese, sempre verberada por Ponty, de uma cisão originária ente consciência e mundo. Uma tal cisão adquire a sua expressão de máxima radicalidade em 1913, quando Edmund Husserl conduz o célebre Gedankenexperiment da Weltvernichtung (aniquilação do Mundo) no $\S 49$ do primeiro volume das Ideias Directrizes para uma Fenomenologia e uma Filosofia Fenomenológica. Husserl determinará aí o carácter absoluto necessário de uma Consciência e a feição relativa e contingente do Mundo. ${ }^{8}$ Mas, de novo, não é da relação com Husserl que cuidamos aqui.

${ }^{8}$ Husserl mostra que a consciência sobreviveria pacificamente a uma hipotética aniquilação do mundo material (isto é, não seria afectada na sua existência actual), enquanto que a hipótese 
Diríamos, portanto, que ao esforço de Kant falta radicalidade e profundidade. A ideia de que a consciência constitui o seu objecto representa um inaceitável esquecimento e dissimulação do sujeito concreto e da experiência perceptiva, quando esta última já não se deixa reconduzir à ideia de uma simples "competência". A tese sempre reiterada pelo autor, aquela que percorre transversalmente os seus textos, é a aquela que, nos antípodas da enunciação anterior, determina que o sujeito não é uma simples "função", mas um concreto. Donde, a reabilitação da experiência não pode ser feita num quadro de representações intelectuais que a informem das respectivas condições de possibilidade (onde precisamente ela se converte numa tal função), mas exactamente fora dessa perspectiva. A subsunção da experiência na consciência, própria do intelectualismo, ignora que há uma vida do sensível que é anterior ao processo de conhecimento, e que se constitui, em qualquer circunstância, como seu irrecusável fundamento. Isso significa, derradeiramente, que confinada à ordem gnosiológica - estratégia sancionada pela doutrina intelectualista (fortemente visada por Ponty no Capítulo III de Fenomenologia da Percepção)-, a sensibilidade não conhece verdadeiramente um processo de autêntica reabilitação ou revalorização. Bem pelo contrário, essa é a posição que culmina na sempre continuada dissimulação do sensível, na subtracção da sua ligação vital ao mundo. A experiência perceptiva é, para Ponty, a mais originária, no sentido em que é aquela que restaura, em sentido pleno, esse laço primordial com o mundo. Tal significa ainda que a experiência sensível originária não é aquela que se determina, à maneira kantiana, como afecção da nossa capacidade representativa; da mesma forma, a sensação não mais deve ser tomada como efeito de um objecto sobre essa mesma capacidade representativa, ou, em termos mais estritamente pontianos, como a invasão do sensível no sentinte. Trata-se antes do sinal mais peremptório da nossa inscrição no mundo, pois, para Ponty, toda a sensação é já uma percepção, ou como dirá no texto de 45 , Fenomenologia da Percepção, «la plus simple des percéptions», que, de sua vez, qualifica uma experiência que, de um só lance, e sem necessidade de mediação, empresta ao sensível a sua irrevogável dimensão originária. O mundo concreto e sensível, franqueado pela experiência perceptiva não é, pois, o mundo das clássicas categorias da clareza e da distinção, expressões mais adequadas para caracterizar o

contrária, leia-se, a da supressão da consciência, implicaria a destruição do mundo material que é simultaneamente o fundamento e o motivo para as nossas percepções. O ser mundo é, nesta perspectiva, e enquanto ser meramente intencional, relativo, não autónomo enquanto que a consciência, o ser imanente, é absoluto ou, numa formulação tipicamente cartesiana, tal que nulla 're' indigeat ad existendum. Eis um testemunho, na primeira pessoa, dessa experiência da aniquilação do Mundo: "Die objektive Welt, die für mich ist, die für mich je war und sein wird, je sein kann mit allen ihren Objekten, schöpft, [...] ihren ganzen Sinn und ihre Seinsgeltung, die sie jeweils für mich hat, aus mir selbst, aus mir als dem transzendentalen Ich, dem erst

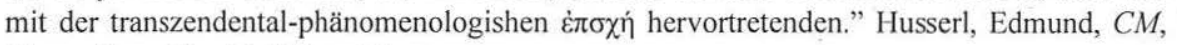
Husserliana, Band I, $\S 11$, p. 27. 
plano eidético que Ponty considera ser a expressão consumada de uma inaceitável abstracção. Isso significa ainda, e de novo contra Kant, que o pensamento não diz da tentativa para engendrar uma unidade de fenómenos via actividade categorial. Isso significa, outrossim, que o entendimento não é uma estrutura autónoma que espontaneamente engendra os seus puros conceitos. Apesar da aparência de uma efectiva revalorização de um sensível quando este se determina como fonte irredutível do conhecimento humano, e pese embora a bondade da decisão que está na sua origem, o resultado é, porém, radicalmente diverso: o da consumada depreciação do sensível, que se deixa pensar numa estrita lógica de contraste com o inteligível.

\section{A ciência clássica ante a exigência fenomenológica do zu den sachen selbst}

Ao pensamento científico moderno, quando sanciona este modelo de inteligibilidade, não restará outra alternativa que o de ser, ele próprio, objecto de um profundo esforço de reorganização que lhe permita simbolizar, de forma inteiramente fidedigna, os fenómenos. Com efeito, para Ponty

é necessário que o pensamento da ciência - pensamento de sobrevoo, ${ }^{9}$ pensamento do objecto em geral-se coloque de novo num aí prévio, in locus, sobre o solo do mundo sensível [...]. ${ }^{10}$

Esse novo modelo de pensamento para a ciência que assim se perfila é aquele que se obtém pela exigência de um recuo às instâncias mais primitivas, vertida na máxima husserliana do zu den sachen selbst (que constituiu o lema de sempre da fenomenologia). Mas este retorno às coisas mesmas para sempre permanecerá incompleto se ele não se fizer acompanhar da exigência complementar de uma expressão exacta e fidedigna de tais coisạs. E isso não significa, para Ponty, fenómenos transparentes, e de uma transparência laboratorialmente construida, mas o dado primordial e bruto, aquele que emerge como sinal da constitutiva obscuridade da percepção e do mundo. A declaração que se segue

9 A propósito desta noção de sobrevoo, que percorre transversalmente a "parte crítica" da filosofia de Ponty, caracterizando negativamente pensamento, sujeito ou ciência, diz Isabel Matos Dias: "La métaphore du survol indique le mouvement de passer "par-dessus», soulignant le déracinement temporel et spatial du sujet constituant, auquel l'auteur oppose l'enfoncement, mouvement d'enracinement propre au sujet situe spatio-temporellement, sujet perceptif." Matos Dias, Isabel, Merleau-Ponty-Une Pö̈́tique du Sensible. Toulouse: Presses Universitaires du Mirail, 2001, p. 23.

10 "Il faut que la pensée de science - pensée de survol, pensée de l'objet en général- se replace dans un «il y a préalable», dans le site, sur le sol du monde sensible [...]." Maurice Merleau-Ponty, L'Eil et L'Esprit. Paris: Gallimard, 1964, p. 12. 
é a categórica expressão da contundente crítica que Merleau-Ponty dirige a um tal modelo de inteligibilidade:

A ciência manipula as coisas e renuncia a habitá-las. Para si estabelece modelos internos das coisas, e operando sobre estes índices ou variáveis as transformações permitidas pela sua definição, só se confrontam de quando em vez com o mundo actual $[\ldots] .^{11}$

Algumas linhas volvidas, e numa tentativa para definir o pensamento da ciência clássica, pode ler-se ainda:

Pensar é experimentar, operar, transformar, com a única reserva de uma verificação experimental, na qual não intervêm senão fenómenos altamente "trabalhados», e que os nossos aparelhos mais que registarem, produzem. $[. . .]^{12}$

Destes passos, algumas consequências se inferem de imediato:

i) a inscrição primitiva das ciências não se faz na esfera do fenómeno trabalhado, mas no quadro do dado primordial e bruto, na exacta medida em que só este último pode exprimir, com inteira fidelidade, a nossa inscrição primitiva - ontológica, e não gnosiológica - no mundo;

ii) a ciência comunica uma autonomia aos seus objectos que estes, estritamente tomados como tais fenómenos trabalhados, efectivamente. não possuem;

iii) a ciência deve abandonar a sua pretensão de possessão relativamente ao mundo, para compreender a sua constitutiva necessidade de o habitar;

iv) a universalidade das ciências não é aquela que se dirige à obtenção de uma universalidade estritamente formal, que vê no apartamento do sensível a condição de possibilidade para a concretização plena do seu propósito.

Detenhamo-nos um pouco mais nesta última afirmação. Ela traduz, derradeiramente, a investidura de uma nova forma de universalidade, uma universalidade sensivel, ou, para retomar aqui a célebre tese kantiana expendida

11 "La science manipule les choses et renonce à les habiter. Elle s'en donne des modeles internes et,opérant sur cês índices ou variables les transformations permises par leur définition, ne se confronte que de loin en loin avec le monde actuel." Ibid., p. 9.

12 "Penser, c'est essayer, opérer, transformer, sous le seule réserve d'un contrôle expérimental où n'interviennent que des phénomènes hautement «travaillés», et que nos appareils produisent plutôt qu'ils ne les enregistrent." Ibid., p. 10. 
na terceira Crítica, de uma universalidade sem conceito, com prejuízo para a perspectiva que determina que a universalidade é a expressão liminar de uma impossibilidade, quando a exigência de radicalidade nos reenvia para o corpo, como sujeito irredutível da experiência perceptiva. Nas suas notas de trabalho que integram o volume formado por textos póstumos publicados por Claude Lefort, intitulado o Visível e o Invisível,. Merleau-Ponty declara não haver mundo inteligível, mas (apenas) mundo sensível. ${ }^{13}$ Haverá que dizer, porém, que, longe de se formalizar aqui a decisão que corta cerce esse horizonte de universalidade - ora entendido ainda como a expressão da supramencionada impossibilidade sempre que se toma a percepção como ponto de partida - o que anima Ponty é a intenção de depor a bașe que converte o pensamento da ciência num artificialismo absoluto. O universal não é a derradeira etapa de um processo de transformação e abstracção - logo, de cisão- do sensível, que se deixa engendrar por uma faculdade estritamente intelectual como o entendimento. Dito de outra forma, este universal deve ser a expressão peremptória de um entendimento que se apresente em estreita continuidade com a exigência fenomenológica de um de retorno às coișas mesmas. Não espanta, por isso, o incitamento, particularmente incisivo em Fenomenologia da Percepção e em Visivel e o Invisivel, para que seja operada uma verdadeira reforma do entendimento, que o expurgue da falsa ideia de uma autonomia das operações lógicas e que o reconduza à concretude da experiência originária e bruta. Uma tal experiência (e notemos que esta experiência "bruta" a que Ponty uma e outra vez se refere é radicalmente diversa da "matéria bruta das sensações" a que Kant se refere na primeira edição da $C R P^{14}$ ) não mais será tomada como o elemento material do fenómeno, e menos ainda como a expressão de um conhecimento menor, porquanto obscuro e confuso, mas como o "cordão umbilical do nosso saber", aquele que revela um pensamento mais antigo relativamente ao qual todo o saber efectivo assoma como expressão segunda ou derivada. Trata-se, pois, de um pensamento sensível, que supera a ideia kantiana de "síntese espontânea de um diverso dado", ou em termos mais estritamente pontianos, que vence a tese da subsunção da experiência numa consciência tomada como pura determinação objectiva. Daí que a decisão kantiana de tomar o conhecimento objectivo como palco para a reabilitação do sensível, esquecendo este fundo pré-predicativo que o antecede e que o torna possível, possa agora ser tomada como um propósito inconsequente. Trata-se de uma moldura compreensiva da sensibilidade que se deixa apoiar ainda na pesporrente perspectiva racionalista,

13 "Il n'y a pas de monde intelligible, il y a monde sensible". Merleau-Ponty, M., Le Visible et l'Invisible. Paris: Gallimard, 1964, p. 263.

14 "A experiência é, sem dúvida, o primeiro produto que o nosso entendimento obtém ao elaborar a matéria bruta das sensações". Kant, Immanuel, Critica da Razão Pura. Lisboa: Fundação Calouste Gulbenkian, 1994 (3. 'a edição), A1, p. 56. 
aquela que dissimula o laço ontológico que nos prende ao mundo (mundo percebido e pré-objectivo ou antepredicativo), e que ostensivamente ignora que

tudo quanto sei acerca do mundo, mesmo através da ciência, sei a partir de uma mirada minha ou de uma experiência do mundo sem a qual os símbolos da ciência não quereriam dizer nada. ${ }^{15}$

Isto significa ainda, como diz Ponty, que

retornar às coisas mesmas é retornar a esse mundo antes da consciência de que a consciência sempre fala, e fora da qual toda a determinação científica é abstracta $[\ldots] .{ }^{16}$

Do que foi dito, deve destacar-se a falência das categorias clássicas para exprimir esse recuo protagonizado pela reflexão fenomenológica. De novo, a ordem gnosiológica deixa-se determinar como um domínio de pura abstracção, na qual o esforço de reabilitação do sensível permanece ainda por concretizar. A percepção é a expressão de um horizonte mais fundo e vertical, que sucessivamente nos escapa quando a procura não ultrapassa o plano derivado do estritamente gnosiológico, e quando se perde definitivamente a perspectiva de profundidade. No entanto, a mesma crítica que determina a falência dessas velhas categorias, mas também da velha linguagem que ora claudica perante a exigência nova de se converter em voz do silêncio, dizia, é a mesma crítica que ora se volve no estímulo decisivo para abraçar a arte e particularmente a pintura moderna, tal como ela se deixa glosar por Cézanne, nesse esforço para superar essa linguagem ainda excessivamente formal. Trata-se ora de uma linguagem indirecta, que empresta "voz ao silêncio" - para retomar aqui a feliz expressão que dá título ao célebre artigo de 1952, dedicado a Sartre, intitulado "Le langage indirect et les voix du silence" - e que exprime a inaudita "condição sensível" do pensamento.

\section{5. É a Razão Sensível uma Razão Estética?}

Não nos cumpre fazer aqui o papel de exegeta, e retomar as sempre revisitadas teses que determinam como, num mesmo pensamento, filosofia fenomenológica e arte podem ser vistas como momentos inseparáveis de uma mesma estratégia e com um fito constante: ver na exigência fenomenológica de retorno às coisas mesmas, e na sua correcta e fidedigna tradução operada pela arte, os

15 "Tout ce que je sais du monde, même par science, je le sais à partir d'une vue mienne ou d'une expérience du monde sans laquelle les symboles de la science ne voudraient rien dire." Merleau-Ponty, M., Phénoménologie de la Perception. Paris: Gallimard, 1945, p. II.

16 "Revenir aux choses mêmes, c'est revenir à ce monde avant la connaissance dont la connaissance parle toujours [...]"“. Ibid., p. III 
passos intermédios que permitam obter, de facto, uma reabilitação da condição da sensibilidade. Esse trabalho, seja dito, está feito e é de todos bem conhecido. Procurarei antes discutir, de forma necessariamente breve, os efeitos da relação dialógica entre Kant e Ponty - aqui simplesmente aflorada nos seus contornos mais elementares - quando o que está em causa é encontrar o ponto que nos permita determinar, sem ambiguidades, o que é verdadeiramente um esforço de reabilitação do sensível e o que mais não é do que um ensejo que meramente se queda no plano formal das intenções. Se, por um lado, Kant não pode deixar de ser considerado como um autor que institui, em bases inteiramente novas, a condição sensível do pensamento humano, por outro esse esforço, quando se deixa pensar à luz de máximas listadas supra como as de radicalidade e profundidade de um pensamento, não pode deixar de ser considerado como uma empresa ainda insuficiente. Em ambos os casos, porém, se nota um mesmo desígnio: prognosticar o estatuto sensível da Razão, ou para retomarmos a expressão que dá título ao texto de Leonel Ribeiro dos Santos, instituir, sem rodeios, a tese de uma "Razão Sensível". A pergunta que se impõe, todavia, é a de saber se uma tal razão sensível é já a categórica expressão de uma razão efectivamente sensível, no sentido mais amplo e antigo de aisthesis, quer dizer, uma razão imbricada na sensibilidade e no sensível, que deixa reconduzir aí todas as suas operações, ou se é ainda a expressão de um intolerável desenraizamento. Dito de outra forma: tem a razão sensível, aquela que é imputável a Kant, e cujas determinações foram aqui apreciadas, o mesmo alcance que uma "razão estética", ${ }^{17}$ no sentido de uma razão já totalmente imbricada na sensibilidade, que é aquela que se deixa assacar ao projecto fillosófico de Merleau-Ponty? A resposta, vimo-lo, é um retumbante não.

Isso não significa, no entanto, que Kant, que aqui apresentámos como advogado da sensibilidade, tenha representado mal o seu constituinte. Significa tão só que o processo de defesa foi ainda instruído num paradigma em que a sensibilidade se deixa pensar como resultado de um processo cujas condições são aclaradas e definidas a montante, como explicitamente propõe a filosofia transcendental. A subjectividade transcendental autónoma que ela pressupõe é (como lembrava Ponty em 45) aquela que parece estar em todo o lado mas que, em bom rigor, não está em parte alguma, e que tão vivamente contrasta com um sujeito perceptivo, situado, pelo seu corpo, no mundo. A reflexão fenomenológica de Ponty é, pois, a que chama a si uma experiência concreta e não simples-

17 Tomamos esta expressão de empréstimo a M. ${ }^{a}$ Cármen López Sáenz: "Podríamos denominarla «razón estética», en el sentido originario de la palabra aisthesis; es decir, una razón que se nutre de lo sensible y de lo sensual [...]." López Sáenz, M.C., "El sentido de la aisthesis en M. Merleau-Ponty", in Santos, J.M./Alves, P.M.S./Barata, A. (coords.), A Fenomenologia Hoje - Actas do Primeiro Congresso Internacional da Associação Portuguesa de Filosofia Fenomenológica. Lisboa: Centro de Filosofia da Universidade de Lisboa, 2002, p. 299. 
mente uma experiência possível, como explicitamente propõe ainda a reflexão transcendental.

Mas a pergunta que apresenta a relação dialógica entre Kant e Ponty na sua expressão mais peremptória, quando se trata de perceber, afinal, qual o impacto de cada um dos filósofos na tarefa sempre inacabada de reabilitação do sensível, é a que se apresenta da forma seguinte: é a Razão Sensivel uma Razão Estética? A resposta já se deixa antever nas considerações expendidas a montante, mas uma solução categórica requer uma derradeira incursão no terreno da tradição que Ponty severamente critica. Na CRP, Kant pretendera mostrar, contra o "excelente analista" Baumgartem, que a sua abordagem relativa à utilização da palavra estética se aproximava mais da linguagem e do sentido dos antigos, quando esta não já não designa simplesmente uma "crítica do gosto", mas quando essa designação é reservada para uma ciência, a ciência de todos os princípios da sensibilidade a priori. O que parece, porém, ter escapado a Kant - tal é, pelo menos, o entendimento do fenomenólogo francês - é que uma tal compreensão, quando se deixa incrustar na problemática do conhecimento objectivo, e enquanto não exprime o mundo pré-objectivo e percebido, aquele relativamente ao qual qualquer tomada de posição da ciência é sempre tardia, exprime ainda uma filiação na longa tradição de desfiguração do sensível. A questão da reabilitação do sensível - que é aquela que, afinal, melhor assimila esse significado antigo de Estética como aisthesis, e que Kant explicitamente chama a si - enquanto se coloca no seio de uma perspectiva gnosiológica, e na exacta medida em que convoca uma subjectividade ainda transcendental, é uma questão que permanece sem resposta.

Não nos apressemos, porém, a postergar o notável esforço de acreditação da sensibilidade agenciado por Kant, quando este liminarmente se recusa a pensar a diferença entre o estético e o lógico do estrito ponto de vista da clareza ou obscuridade das respectivas representações, e quando percebe que a reabilitação da Estética invoca, afinal, a própria revalorização da sensibilidade como sua inalienável condição de possibilidade. Este foi o decisivo passo que não foi observado por Baumgarten, mas este parece ter sido também o passo que Kant considera ter cumprido, mas que, em bom rigor, não concretizou cabalmente.

Como se vê, a intenção kantiana de recuperar o sentido dos antigos de Estética, que é o que implica correlativamente a reabilitação plena do sensível, parece, na verdade, não ser mais do que a expressão de um projecto adiado ou inacabado, a que Ponty - na assunção plena da irredutibilidade epistemológica que o separa irremediavelmente do projecto kantiano - concederá a sua forma última e derradeira. 


\begin{abstract}
In this paper, we want to address the Merleau Ponty's thesis which states that occidental philosophical tradition mistreats sensibility. It's. not as we had some kind of substantial doubt regarding this statement which is, in fact, historically and philosophically accurate. However, what is not clear enough is the reason for disregarding the notable effort developed by Kant to restore its value and importance. Thus, we will first attend Kant's sensibility doctrine which underlies both knowledge and taste, and concentrate subsequently on the reasons for the diagniosis of its insufficiency, according to the principles established by Merleau-Ponty's theoretical perspective. A final question regarding the distinction between a "Sensitive Reason" and a so called "Aesthetic Reason" will guide the reader trough the central assumptions that lie behind this critical assessment expounded by Merleau-Ponty's new ontology.
\end{abstract}


